\title{
Pengembangan Karakter Ikari Shinji Dalam Anime Neo Genesis Evangeliom
}

\author{
Adriel Hans Wahyudi ${ }^{* *}$, Marisa Rianti Sutanto ${ }^{2^{*}}$ \\ Program Studi Sastra Jepang, FBB, Universitas Kristen Maranatha \\ Bandung-Jawa Barat \\ 1[adrielhanswahyudi@gmail.com]2[sutantomarisarianti@gmail.com]
}

\begin{abstract}
Abstrak
Penelitian ini membahas pengembangan karakter tokoh utama Ikari Shinji pada seri anime Neon Genesis Evangelion, yang bertujuan untuk memahami bagaimana tokoh Ikari Shinji dikembangkan dalam cerita. Metode yang digunakan dalam penelitian ini adalah deskriptif kualitatif. Hasil dari penelitian menunjukkan bahwa Ikari Shinji pada awal cerita memiliki 'kebohongan' yang ia percayai, yaitu melarikan diri dari masalah. Namun, ia memiliki potensi untuk mengalahkan 'kebohongan' tersebut. Sepanjang cerita ia merasakan konsekuensi dari 'kebohongannya', ia juga menemukan kebenaran dan apa yang sebenarnya ia butuhkan. Pada satu titik ia harus membuat keputusan antara kebenaran dan 'kebohongannya'. Hasilnya adalah diri Ikari Shinji yang lama menjadi 'mati' setelah ia membuat keputusan tersebut. Ia meninggalkan 'kebohongannya' dan membuktikan bahwa dirinya telah berkembang menjadi pribadi yang lebih baik. Akhir cerita merupakan jawaban atas pertanyaan tematik anime ini.
\end{abstract}

Kata Kunci: anime, cerita, pengembangan karakter, tokoh fiksi

\begin{abstract}
This research discusses the character development of the main character Ikari Shinji from the anime Neon Genesis Evangelion. To interpret the character of the main character, the method used is descriptive kualitative, and the analysis refers to Weiland's theory of character development. The results of the research show that Ikari Shinji at the beginning of the story has a 'lie' that he believes in, namely running away from problems. However, he has the capability to beat 'thelie'. Throughout the story he gets the consequences of his 'lie', he also finds out the truth and what he actually needs. At one point he had to make a decision between the truth and the 'lie'. The result was Ikari Shinji's old self becomes 'dead' after he made that decision. He left the 'lie' and proved that he had developed into a better person. The story's ending is the answer to this anime thematic question.
\end{abstract}

Keyword: anime, story, character development, fictional character 


\section{Pendahuluan}

Dalam sebuah cerita, tokoh-tokoh merupakan keutamaan yang membuat kita sebagai penonton memiliki ikatan emosional dan intelektual dengan cerita tersebut (Lewis, 2013). Menurut Weiland (2016), pengembangan karakter adalah perjalanan seorang tokoh dalam suatu jalur cerita. Perjalanan tokoh dalam cerita bermula dari titik awal dari sang tokoh, pelajaran-pelajaran yang sang tokoh dapatkan sepanjang cerita berlangsung dan titik akhir yang dicapainya pada akhir cerita. Dengan mengamati perjalanan tokoh tersebut, penonton tidak hanya dapat menyaksikan dan merasakan apa saja yang dialami oleh sang tokoh namun juga berkembang dan belajar bersama sang tokoh karena adanya ikatan hubungan intelektual dan emosional tersebut, walaupun terjadi secara tidak langsung.

Neon Genesis Evangelion adalah sebuah seri anime karya Hideaki Anno yang menceritakan perjuangan umat manusia melawan para shito menggunakan robot raksasa yang dinamakan Evangelion. Shito adalah mahluk supranatural yang mengancam eksistensi umat manusia. Sekilas Evangelion nampak seperti anime dengan genre super robot lainnya, namun yang menjadi sorotan utama dalam Evangelion bukanlah pertarungan antara robot raksasa melawan monster, melainkan konflik psikologis yang dialami oleh tokoh-tokoh dalam anime ini.

Tokoh utama dari Evangelion adalah Ikari Shinji, seorang anak berusia 14 tahun yang dihubungi oleh ayahnya, Ikari Gendou, untuk menjadi pilot dari EVA-01 setelah sekian lama mereka tidak bertemu satu sama lain. Shinji pada awal cerita merupakan sosok yang seringkali melarikan diri dari masalah dalam hidupnya dan memandang dirinya sebagai seseorang yang tidak berguna. Sepanjang cerita, Shinji tidak hanya harus melawan shito yang mengancam umat manusia, ia juga harus bertumbuh dan berkembang menjadi pribadi yang lebih baik. 
Rumusan masalah dalam penelitian ini adalah bagaimana pengembangan tokoh Ikari Shinji pada seri anime Neon Genesis Evangelion yang terefleksi melalui perjalanan tokoh dalam cerita, yaitu bermula dari titik awal dari sang tokoh, pelajaran-pelajaran yang sang tokoh dapatkan sepanjang cerita berlangsung dan titik akhir yang dicapainya pada akhir cerita.

\section{Metode dan Teori}

\subsection{Metode Penelitian}

Metode yang digunakan dalam penelitian ini adalah metode deskriptif analisis. Menurut Taylor (2005), metode ini merupakan langkah bagi peneliti untuk melacak seluruh aspek dalam cerita, yaitu tokoh-tokoh selain tokoh utama, latar dan kejadian dalam cerita secara holistik. Perlunya dilakukan hal ini adalah untuk menemukan alasan dan tujuan atas aksi yang dilakukan oleh Ikari Shinji, serta untuk menemukan dampak dari pengalaman Ikari Shinji terhadap pengembangan karakternya.

\subsection{Teori}

Teori yang digunakan dalam penelitian ini adalah teori pengembangan karakter menurut Weiland (2016). Pengembangan karakter suatu tokoh dapat diringkas menjadi tiga langkah sederhana yaitu: (1) sang tokoh berawal atau mulai dari suatu titik, (2) sang tokoh sepanjang jalannya cerita belajar berbagai hal, (3) sang tokoh pada akhir cerita mungkin berakhir di titik yang berbeda dan mungkin berakhir lebih baik dari titik awalnya.

Weiland (2016) mengemukakan tiga jenis character arc yang terjadi pada tokoh dalam cerita, yaitu positive character arc, negative character arc, dan neutral character arc. Pada analisis berikut akan dibahas mengenai positive character arc sebagai arah pengembangan karakter yang terjadi pada tokoh utama Ikari Shinji. 


\section{Kajian Pustaka}

Penelitian terdahulu yang pernah dilakukan terhadap anime Neon Genesis Evangelion adalah sebagai berikut. Napier(2002), melakukan analisis komparatif tentang fantasi, realita dan identitas terminal dalam anime Evangelion dan Serial Experiments Lain, kemudian Redmond (2007), melakukan penelitian mengenai Evangelion sebagai produk budaya dari Asia Timur, sedangkan Ortega (2007) melakukan analisis tentang hubungan Evangelion dan kepercayaan Yudeo-Kristen. Berdasarkan acuan yang didapat mengenai penelitian terdahulu tersebut, analisis terhadap anime Neon Genesis Evangelion dengan menggunakan teori character arc (Weiland, 2016) belum dilakukan.

\section{Hasil dan Pembahasan}

Ikari Shinji pada awal cerita merupakan seorang remaja yang seringkali melarikan diri dari masalah yang ada dan memandang rendah dirinya sendiri, dan pada akhir cerita ia belajar untuk menghadapi masalah dan menerima dirinya sendiri. Berikut adalah pengembangan karakter Ikari Shinji dalam cerita seri anime Neon Genesis Evangelion.

\subsection{Kebohongan Yang Dipercaya Oleh Ikari Shinji}

Dalam pengembangan karakter, 'kebohongan' yang dipercayai oleh sang tokoh tidak selalu dijelaskan secara eksplisit, melainkan secara implisit (Weiland, 2016:12-16). 'Kebohongan' tersebut berdampak pada sang tokoh yang membuat tokoh tersebut melakukan suatu tindakan, mempengaruhi pandangannya terhadap dunia dalam cerita dan perasaannya. Dengan mengamati tindakan yang dilakukan oleh Ikari Shinji, 'kebohongan' yang ia percayai dapat ditemukan.

Pada episode 1, Shinji diantar oleh Katsuragi Misato agar ia dapat bertemu dengan 
ayahnya di Tokyo-3, sambil menghindari shito yang sedang menyerang Tokyo-3. Sesampainya di markas NERV, Shinji diminta untuk menjadi pilot EVA-01 untuk melawan shito yang sedang menyerang Tokyo-3, yaitu shito yang sama yang dilihat oleh Shinji pada awal episode 1. Namun Shinji menolak permintaan tersebut. Shinji menolak untuk menjadi pilot EVA-01 dengan alasan ia merasa tidak sanggup, dan ia menganggap dirinya tidak mendapatkan informasi apa pun tentang hal tersebut, sebagaimana tertera pada kutipan berikut.

(1) 碇シンジ：無理だよそんなの‥見たこと聞いたことがないのに、できる わけないよ!

(Neon Genesis Evangelion, Episode 1, menit 14:54-15:40)

Ikari Shinji : Muri dayo sonna no... Mita koto kiita koto ga nai no ni, dekiru wake nai yo!

Ikari Shinji : Ini tidak mungkin... Aku tak pernah melihat dan mendengar tentang hal ini, mana mungkin aku bisa!

Mendengar perkataan Shinji demikian, Gendou memberi perintah untuk menggunakan pilot lain mereka, yaitu Ayanami Rei untuk menjadi pilot EVA-01 menggantikan Shinji. Mengetahui perintah dari Gendou demikian, Shinji merasa bahwa dirinya adalah orang yang tidak berguna.

(2) 碇シンジ：やっぱり僕は要らない人間なんだ。

(Neon Genesis Evangelion, Episode 1, menit 17:03-17:06)

Ikari Shinji : Yappari boku wa iranai ningen nanda.

Ikari Shinji : Sudah kuduga, aku ini orang yang tidak berguna.

Berdasarkan tindakan dan keputusan Ikari Shinji tersebut, dapat dipahami bahwa: 
(1) Shinji tidak memiliki rasa percaya diri yang tinggi, (2) Shinji lebih mementingkan dirinya sendiri, (3) Shinji lebih memilih untuk menghindari masalah dibandingkan menghadapinya, (4) Shinji memandang dirinya sendiri sebagai seorang yang tidak berguna dan mudahuntuk digantikan. Keempat hal ini menunjukkan bahwa 'kebohongan' yang dipercayai oleh Ikari Shinji adalah, "lebih baik aku berlari dari masalah yang ada."

Shinji sesungguhnya mengetahui akibat apabila ia terus berpegang pada kebohongannya, bahwa masalah yang dihadapinya akan menjadi semakin parah dan dapat mengakibatkan orang-orang di sekitarnya terkena dampak atas tindakannya. Kemudian, Shinji mengucapkan「にげちやダメだ」 (episode 1, menit 18:32-18:40) (nigecha dame da - jangan kabur) berulang-ulang pada dirinya sendiri. Tindakan ini menandakan bahwa ia sebenarnya mengetahui bahwa dalam menghadapi masalah, sebagaimana pun menakutkan masalah itu, ia tidak boleh melarikan diri. Hal-hal ini merupakan penanda bahwa sebenarnya Ikari Shinji memiliki potensi untuk melampaui 'kebohongan'nya.

Shinji kemudian memutuskan untuk menjadi pilot dari EVA-01. Hal yang memotivasi Shinji untuk menjadi pilot pada saat itu adalah agar Rei yang sedang cidera tidaklah menjadi celaka. Keputusan ini adalah langkah pertama yang Shinji ambil untuk bertumbuh dan berkembang, dan yang lebih penting adalah ia belajar untuk menghadapi masalah melalui keputusan tersebut.

\subsection{Kesulitan Yang Dialami Ikari Shinji Karena Kebohongannya}

‘Kebohongan’ Ikari Shinji yaitu 'lebih baik aku berlari dari masalah yang ada', tidak hanya terhadap tugasnya sebagai pilot Evangelion yang melawan shito, namun berimbas terhadap hubungannya dengan orang lain. Shinji seringkali menutup dirinya terhadap orang lain. Dalam berinteraksi dengan orang lain, ia cenderung mengambil 
peranan pasif di dalam melakukan percakapan. Ia hanya berkomunikasi jika ada yang bertanya kepadanya dan jarang sekali memulai percakapan. Hal ini berakibat ia menjadi canggung apabila harus memulai suatu percakapan dengan orang lain.

Kecanggungan tersebut nampak saat Shinji mengirimkan kartu keanggotaan yang telah direvisi kepada Rei atas permintaan Ritsuko (episode 5, menit 13:29-17:18). Sifat Rei yang pendiam dan misterius ini membuat Shinji kesulitan dalam berinteraksi dengannya. Akan tetapi, tidak hanya dalam berinteraksi dengan Rei, Shinji juga mendapat rekanan pilotbaru yang datang dari Jerman bernama Asuka Langley Soryu, dan di episode 8 akan mulai bekerja sama dengan Shinji untuk bertempur melawan shito. Berlawanan dengan Rei, Asuka memiliki sifat yang dominan, arogan dan konfrontatif kepada rekanan seusianya, terutama terhadap Shinji. Sifat dan perilaku Asuka demikian membuat Shinji semakin enggan berinteraksi dengannya.

‘Kebohongan’ Ikari Shinji juga membuat dirinya seringkali membuat keputusan untuk berhenti sebagai pilot dan keluar dari NERV. Namun keputusan-keputusan tersebut tidak berlangsung lama dikarenakan Shinji segera kembali kepada tugasnya sebagai pilot, seperti pada episode 4, dan pada episode 19. Pada episode 4, Shinji memutuskan untuk keluar dari NERV, karena menjadi seorang pilot baginya adalah hal yang sulit dan dapat mengancam nyawanya. Pada bagian akhir episode tersebut ia tetap melanjutnya tugasnya sebagai pilot karena merasa dirinya telah diterima oleh orang-orang di sekitarnya, seperti teman-teman sekolahnya, Touji dan Kensuke, juga anggota NERV lainnya seperti Misato dan Rei. Perubahan kehidupannya dalam menjalani peranan sebagai pilot membuat Shinji menemukan 'rumah' baru baginya.

Pada episode 19, Shinji memutuskan untuk keluar dari NERV dikarenakan tindakan manipulatif Gendou, ayahnya, yang membuat Shinji secara tidak langsung menyebabkan Touji, temannya, terluka parah (terjadi pada episode 18). Shinji 
memutuskan untuk keluar dari NERV pada saat itu karena ia marah dan tidak suka pada perbuatan Gendou. Akan tetapi, Shinji tidak juga keluar dari NERV karena ia melihat dan menyadari bahwa tanpa dirinya, NERV tidak sanggup untuk melawan shito dan mengetahui konsekuensi kemusnahan umat manusia, termasuk dirinya sendiri, apabila para shito menang.

\subsection{Kebenaran yang Ikari Shinji Butuhkan}

Pada episode 16, menit 13:34-16:02, Shinji sedang duduk di dalam sebuah kereta, adegan ini nampaknya terjadi dalam mimpi atau pikiran Shinji. Ia menyadari keberadaan sosok lain yang ada bersamanya, sosok tersebut merupakan shito yang menelannya. Shito tersebut dalam adegan ini memiliki suara yang serupa dengan suara Shinji dan wujudnya saat masih anak-anak. Sepanjang adegan interaksi Shinji dengan shito, shito tersebut mengonfrontasi Shinji apakah ia akan terus berlari dari kenyataan dan membohongi dirinya sendiri (episode 16, menit 15:03-16:02). Shinji terus membela dirinya dari dakwaan shito tersebut, mengutarakan alasan bahwa tidak ada salahnya manusia melarikan diri dari rasa sakit yang ada. Kebenaran yang dipahami adalah Shinji tidak dapat terus berlari dari setiap masalah yang muncul.

Pada episode 24, Kaworu, teman baru Shinji memberitahu Shinji apa yang sebenarnya ia butuhkan dalam hidupnya, yang dapat dipahami melalui kutipan berikut.

（3）渚カヨル：一時的接触を極端に避けるね、君は。恐いのかい?人と触 れ合うのが。他人を知らなければ裏切られることも互いに 傷つくこともない。でも、さびしさを忘れることもないよ。 人間はさびしさを永久になくすことはできない。人は一人 だからね。ただ忘れることができるから、人は生きていけ るのさ。

(Neon Genesis Evangelion, Episode 24, menit 09:01-09:25) 
Nagisa Kaworu: Ichijiteki sesshoku o kyokutan ni yokeru ne, kimi wa. Kowai no kai? Hito to fureau no ga. Tanin wo shiranakereba uragirareru koto mo tagai ni kizutsuku koto mo nai. Demo, sabishisa wo wasureru koto mo nai yo. Ningen wa sabishisa o eikyuu ni nakusu koto wa dekinai. Hito wa hitori da kara ne. Tada wasureru koto ga dekiru kara, hito wa ikite ikeru no sa.

Nagisa Kaworu : Kamu sering sekali menghindari kontak dengan orang lain ya? Apakah kau takut? Untuk berinteraksi dengan yang lain? Seandainya kau tidak kenal dengan orang lain, kau tak akan dikhianati dan saling melukai. Tapi, juga akan terus merasa kesepian. Manusia tidak pernah bisa menghilangkan rasa kesepiannya sendiri. Manusia bisa terus lanjut hidup karena mereka mampu untuk melupakan.

Apa yang diucapkan Kaworu pada kutipan tersebut merujuk pada metafora psikologi yang disebut hedgehog 's dilemma. Metafora tersebut mengibaratkan hubungan manusia dengan sesamanya seperti sekumpulan landak yang berdekatan untuk saling menghangatkan satu sama lain. Mereka membutuhkan kedekatan dengan sesama tetapi harus menjaga jarak agar mereka tidak saling melukai (Schopenhauer, 1851: 651 -652). Percakapan berikut juga menegaskan hal tersebut.

(4) 渚カヨル：常に人間は心に痛みを感じている。心が痛がりだから、 生きるのも辛いと感じる。ガラスのように繊細だね。特に君の心は。 碇シンジ：僕が?

渚カヨル：そう。コイに值するよ。

碇シンジ：コイ

渚カタル：好きって事さ。

(Neon Genesis Evangelion, Episode 24, menit 09:46-10:05)

Nagisa Kaworu: Tsune ni ningen wa kokoro ni itami o kanjite iru. Kokoro ga itagari da kara, ikiru no mo tsurai to kanjiru. Garasu no you ni sensai da ne. Toku ni kimi no kokoro wa.

Ikari Shinji : Boku ga? 
Nagisa Kaworu: Sou. Koi ni atai suru yo.

Ikari Shinji : Koi...?

Nagisa Kaworu: Suki tte koto sa.

(Neon Genesis Evangelion, Episode 24,09:46-10:05)

Nagisa Kaworu: Manusia biasanya merasakan rasa sakit di hati mereka. Karena rasa sakit itu, hidup ini menjadi terasa sulit. Sungguh rapuh seperti kaca. Terutama hatimu.

Ikari Shinji : Hatiku?

Nagisa Kaworu: Benar. Layak untuk dicintai.

Ikari Shinji : Cinta?

Nagisa Kaworu: Aku suka padamu.

$「 コ イ 」(k o i)$ yang dimaksud oleh Kaworu ini dapat memiliki berbagai arti, dan juga ucapannya kepada Shinji 「好きってことさ」(suki tte koto sa). Menurut Lewis (1960), ada empat jenis cinta yaitu: storge (cinta antara keluarga), philia (cinta antara teman), eros (cinta antara pasangan hidup, atau hasrat seksual), dan agape (cinta yang tidak memiliki syarat). Berdasarkan interaksi antara Kaworu dan Shinji, cinta Kaworu kepada Shinji merupakan agape, di mana Kaworu bersedia untuk menerima Shinji apa adanya.

Hingga episode 24, tidak ada tokoh yang dengan eksplisit mengatakan bahwa mereka ingin menerima Shinji apa adanya selain Kaworu. Bahkan Gendou, ayah kandung Shinji, melihat Shinji sebatas seorang anggota NERV yang bekerja untuknya. Peristiwa ini menunjukkan bahwa Shinji takut terluka dan melukai jika ia menjalin hubungan dengan orang lain, namun ia juga menyadari tidak dapat hidup sendiri. Ia membutuhkan seseorang yang mampu untuk menerima dirinya apa adanya.

\subsection{Keputusan Ikari Shinji Antara Kebenaran dan Kebohongannya}

Pada episode 24, saat Shinji harus mengejar Kaworu yang ternyata adalah shito, 
ia sempat merasa ragu karena Kaworu adalah seseorang yang mau untuk menerima dirinya apa adanya. Shinji ingin agar Kaworu tetap hidup, namun Kaworu adalah shito yang ditugaskan untuk memusnahkan manusia. Apa yang Shinji butuhkan selaras dengan apa yang ia inginkan tercermin pada sosok Kaworu.

Shinji berada di antara apa yang ia inginkan, Kaworu sang shito, dan apa yang ia butuhkan, seseorang yang mampu untuk menerima dirinya dan menyelamatkan umat manusia. Shinji tahu bahwa tugasnya sebagai pilot NERV adalah untuk mengalahkan para shito, namun Shinji pada titik itu belum sadar bahwa seseorang yang mampu untuk menerima dirinya tidak hanya Kaworu.

Kaworu yang hampir menang pada titik terakhir memahami apa yang selama ini para manusia berusaha untuk lakukan, yaitu untuk terus hidup (episode 24, menit 20:2420:40). Kaworu kemudian membiarkan dirinya untuk dibunuh oleh Shinji agar umat manusia termasuk Shinji dapat terus hidup. Ucapan terakhir Kaworu kepada Shinji (episode 24, menit 21:05-21:32) yang akhirnya meyakinkan Shinji untuk terus hidup dan membunuh Kaworu. Shinji memilih untuk tetap hidup, menjalankan tugasnya sebagai anggota NERV, namun ia masih harus mencari seseorang yang dapat menerima dirinya.

\subsection{Matinya Diri Ikari Shinji Yang Lama}

Pada episode 24, setelah Shinji membunuh shito terakhir sekaligus temannya Kaworu, ia kemudian menyadari kemiripan antara dirinya dengan Kaworu. Dapat disimpulkan bahwa kematian Kaworu adalah ‘kematian’ Shinji yang lama. Kini Shinji telah meninggalkan masa lalunya, yaitu saat ia terus berlari dari berbagai masalah yang seharusnya ia hadapi. Sekarang, Shinji melakukan hal yang benar, baik sebagai pilot NERV dan sebagai pribadi yang lebih baik. Shinji mengakui bahwa sepanjang hidupnya ia akan menghadapi banyak rasa sakit dan kesulitan, namun ia tetap harus hidup apapun 
yang terjadi.

\subsection{Ikari Shinji Membuktikan Bahwa Ia Telah Berkembang}

Pada episode 25 dan 26 seluruh tokoh dalam Evangelion masuk dalam 人類補完 計画 (jinrui hokan keikaku) atau human instrumentality project, yang merupakan upaya SEELE dan Gendou untuk menggunakan third impact yang mereka picu sendiri sebagai katalis dengan tujuan menyatukan seluruhjiwa manusia yang masih hidup dan sudah mati sehingga menjadi satu kesatuan. Instrumentality project tersebut dilaksanakan untuk mencapai kedamaian antara seluruh umat manusia dan menutupi kelemahan satu -sama lain dengan menjadi satu kesatuan.

Pada episode 25, menit 19:36-21:59, Shinji diinformasikan bahwa 'dunia' tempatnya berada saat itu adalah hasil dari keinginannya. Kini Shinji hidup di dalam 'dunia' yang dapat ia ubah sesuai dengan keinginannya. Shinji berada dalam 'dunia' di mana hanya ada dirinya sendiri, di mana kehidupan dan kematiannya dapat ditentukan oleh dirinya sendiri. Shinji menyangkali bahwa ia menginginkan 'dunia' seperti itu, namun tokoh-tokoh lainnya mengonfrontasinya dengan mengatakan bahwa ini adalah 'dunia' yang Shinji inginkan, yaitu tempat ia dapat melindungi dirinya dari rasa sakityang pernah ia rasakan. Shinji kemudian menyadari bahwa ia tidak dapat hidup dalam 'dunia' seperti itu.

Pada episode 26, menit 03:27-04:37, Shinji mendapat pertanyaan mengenai sebab ia tidak boleh melarikan diri. Ia menjawab bahwa hasil melarikan diri adalah rasa sakit bagi dirinya. Shinji mengakui bahwa ia tidak melarikan diri karena ia tidak ingin ditinggalkan, bahwa sepanjang masa itu Shinji takut merasakan kesakitan pada hidupnya. Tokoh-tokoh lain membuat Shinji sadar bahwa tidak hanya dirinya saja yang kesakitan, namun semua orang juga mengalami hal yang serupa. 
Shinji menyadari bahwa walaupun ia ada di 'dunia' rekaan tersebut, ia tetap tidak dapat merasakan eksistensinya, ia tetap merasa kosong. Tanpa adanya orang lain, ia tidak dapat melakukan apapun. Ia bahkan tidak dapat mengenali dirinya. Shinji kemudian menyadari bahwa ia membutuhkan orang lain dan menjadi sendiribukanlah halyang baik. (episode 26, menit 13:00-14:16)

Kemudian, Shinji mengalami salah satu 'dunia' dimana ia tidak menjadipilot dan menjadi anak sekolah biasa (episode 26, menit 14:15-18:47). Di dunia tersebut ia terlihat lebih bahagia hidup secara normal dengan teman-temannya, bahkan ia tinggal dengan orangtua yang menyayanginya, Gendou dan Yui. Shinji menyadari bahwa kenyataan mungkin tidak seburuk yang ia kira, ia memiliki kemampuan untuk membuat keputusan yang akan mempengaruhi hidupnya. Ia akhirnya menyadari bahwa semua yang terjadi di dunia, seluruh hal yang menyenangkan dan menyakitkan bergantung pada cara ia memandang dunia tersebut (episode 26, menit 19:10-20:25)

Pada episode 26, menit 20:38, Shinji mengakui bahwa ia membenci dirinya, menganggap dirinya seorang pengecut, seorang yang licik dan lemah. Namun ia diberitahu oleh tokoh-tokoh lain bahwa kini ia telah mampu menerima dirinya sendiri, dan telah mampu mengurus dirinya sendiri. Pada menit 20:56, Shinji mengatakan bahwa walaupun ia membenci dirinya sendiri, ia ternyata tetap dapat mencintai dirinya. Shinji kini telah dapat memahami, bahwa walaupun dirinya tidak sempurna, ia tetaplah harus menerima dirinya apa adanya. Ia tidak harus hanya bergantung kepada orang lain untuk menerima dirinya, melainkan ia dapat memulai menjadi orang yang lebih baik dengan menerima terlebih dahulu dirinya sendiri. Shinji kemudian menyatakan bahwa ia telah menemukan nilai di dalam dirinya dan memutuskan bahwa ia akan terus hidup di dunia nyata (episode 26, menit 21:06-21:20). 


\title{
4.7 Ikari Shinji Menjawab Pertanyaan Tematik Pada Cerita
}

Dalam keseluruhan cerita Neon Genesis Evangelion ini, tokoh utama Shinji tidak hanya harus melawan shito namun juga harus berhadapan dengan masalah di dalam dirinya. Shinji pada awal cerita lebih memilih untuk melarikan diri dari masalahmasalahnya. Pertanyaan tematik yang dapat dipertanyakan adalah "Apakah Shinji akan menghadapi masalah yang telah ada dan yang akan ada kemudian?'. Shinji menjawab pertanyaan tersebut melalui kutipan berikut.

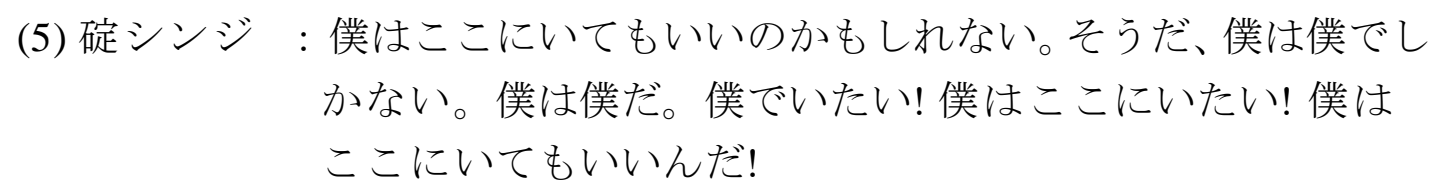

(Neon Genesis Evangelion, Episode 26,21:03-21:20)

\author{
Ikari Shinji : Boku wa koko ni itemo ii no kamo shirenai. Sou da, boku ha boku \\ de shikanai. Boku ha bokuda. Bokude itai! Boku ha koko ni itemo \\ ii nda!
}
Ikari Shinji : Mungkin tidak ada salahnya aku ada di dunia ini. Benar, aku adalah diriku. Aku ingin terus hidup sebagai diriku! Aku ingin hidup di dunia ini! Keberadaanku di dunia ini adalah hal yang baik!

Dunia' yang dimaksud oleh Shinji bukanlah dunia rekaan intrumentality, melainkan dunia nyata sebelum ia masuk ke dalam instrumentality. Shinji menolak apa yang ditawarkan oleh instrumentality walaupun di dalamnya, ia dapat melakukan apapun. Shinji memilih untuk menghadapi dunia yang nyata dibandingkan melarikan diri dalam dunia rekaan instrumentality.

\section{Simpulan}

Berdasarkan teoripengembangan karakter menurut Weiland, anime Neon Genesis 
Evangelion memperlihatkan perjalanan tokoh Ikari Shinji untuk menjadi pribadi yang lebih baik melalui interaksi dengan tokoh-tokoh lainnya dan keputusan yang ia buat. Pada awal cerita, Ikari Shinji memiliki 'kebohongan' yang terus menghalanginya untuk berkembang. Sepanjang cerita, ia harus menghadapi konsekuensi dari 'kebohongannya', menyadari apa yang sebenarnya ia butuhkan dan yang harus ia lakukan. Hingga pada akhir cerita, Ikari Shinji dapat membuktikan bahwa ia telah menjadi pribadi yang lebih baik dengan benar-benar meninggalkan 'kebohongannya', ia berhasil memenuhi kebutuhannya dan melakukan hal yang benar.

\section{Daftar Pustaka}

Hideaki, Anno. (1995). Neon Genesis Evangelion. Japan: Gainax Co., Ltd.

Lewis, C.S. (1960). The Four Loves, London: Geoffrey Bless.

Lewis, Jon. (2013). Essential Cinema: An Introduction to Film Analysis. Oregon: Oregon State University, 33-34.

Napier, S. (2002). When the Machines Stop: Fantasy, Reality, and Terminal Identity in "Neon Genesis Evangelion" and "Serial Experiments Lain". Science Fiction Studies, 29 (3), 418-435. Retrieved May 18, 2021, from http://www.jstor.org/stable/4241108

Ortega, M. (2007). My Father, He Killed Me; My Mother, She Ate Me: Self, Desire, Engendering, and the Mother in Neon Genesis Evangelion. Mechademia 2, 216-232. https://doi.org/10.1353/mec.0.0010

Pasya, Muhammad Sultan, Isti Siti Saleha Gandana, Nia Nafisah. (2020). The Journey of the Villain: A Character Analysis of the Once-Ler from Dr. Seuss'The Lorax. Passage2020, 8 (3), 107-121.

https://ejournal.upi.edu/index.php/psg/article/view/29876

Redmond, Dennis. (2010). Anime and East Asian Culture: Neon Genesis Evangelion. Quarterly Review of Film and Video, 24(2), 183-188. https://doi.org/10.1080/10509200500486205

Schopenhauer, Arthur. (1851). Parerga and Paralipomena: Short Philosophical Essays, Volume 2. Oxford: Oxford University Press, 33-34.

Taylor, Steven J., Robert Bogdan, Marjoire DeVault. (2015). Introduction to Qualitative 
Research Methods: A Guidebook and Resource, New Jersey: John Wiley \& Sons, Inc., 7.

Weiland, K.M. (2016). CREATING CHARACTER ARCS The Masterful Author's Guide to Uniting Story Structur6e, Plot, and Character Development, Scottsbluff: PenForASword Publishing. 